\title{
Spotlight on authentic learning: Student developed digital video projects
}

\author{
Matthew Kearney and Sandy Schuck \\ University of Technology, Sydney
}

\begin{abstract}
The recent convergence of video and computer technologies presents new opportunities and challenges in education. Video production resources such as cameras and video editing software are now widely available in many schools and homes. The ease of use of these resources has encouraged teachers to use them across the curriculum with students of all ages. Furthermore, students often find this work exhilarating and perceive these tasks as deeply relevant and highly contextual. This paper probes the authentic nature of student developed video projects and builds on the literature relating to authentic learning with new educational technologies.
\end{abstract}

\section{Introduction}

Over the past decade, digital video editing software has developed from an expensive, rather clumsy tool, to a cheaper, user friendly tool with many capabilities that facilitate learner control. This development has given rise to a host of new applications in education, including the ability of students to capture, edit and generate their own video. As a result, student generated digital video projects (referred to subsequently in this paper as $D V$ tasks or $D V$ projects) are now being used in many classrooms to support, extend, or change pedagogy and curriculum outcomes.

The project on which this paper is based studied the use of student generated digital video in five schools. Two foci of the project were the nature of student learning from DV tasks and the pedagogical approaches being used with this technology. One of the characteristics of the video tasks that was noted in the study was their authentic nature. This paper analyses current understandings of authentic learning, examines teacher and student beliefs about the perceived authentic nature of student generated digital video tasks, and provides evidence of the authentic learning noted in the DV tasks from the study. 


\section{Background literature}

There has been extensive literature discussing the use of digital video for teaching and learning. In recent times, with the development of software that is more accessible, both in terms of price and ease of use, student generated DV is becoming more commonplace. As a result, the use of student generated DV in schools is increasingly becoming an area of interest to researchers of ICT in education. This paper focuses on one characteristic of such usage in five schools: the authentic learning that arose through the student generated DV task environment.

\section{Authentic learning}

There is general agreement that authentic tasks provide real world relevance and personal meaning to the learner, although issues of what constitutes authenticity and how to design authentic learning tasks are still emerging (Radinsky, Bouillion, Lento \& Gomez, 2001). Useful initial developments have drawn on situated learning theory and suggest that authentic activities can simply be defined as "ordinary practices of the culture" (Brown, Collins \& Duguid, 1989, p.34). However, it should be noted that learning environments cannot be 'pre-authenticated' by teachers, designers or even communities of practice (Petraglia, 1998), and ultimately authenticity "lies in the learner perceived relations between the practices they are carrying out and the use value of these practices" (Barab, Squire \& Dueber, 2000, p. 38).

CTGV (1990) believe authentic tasks involve 'life like' tasks, which require decision making and exposure to real world information, and also allow students to generate their own problems to solve. They also delineate task, factual and process levels of authenticity. Task authenticity refers to the extent to which tasks are realistic and offer problems encountered by real world practitioners. Factual authenticity refers to how particular details of a task (such as characters, instruments etc) are similar to the real world, while a process level of authenticity refers to how learner practices are similar to those practices conducted outside of school.

Radinsky et al. (1998) used two useful models of authentic learning environments: a simulation model and participation model. Tasks that fit a simulation model of authenticity use the classroom as a 'practice field' (separate from the 'real community') but still provide contexts where learners can practise the kind of activities they might encounter outside of school. These tasks are valuable in that support is available from a teacher, but have limitations, as they are not an integral part of the ongoing activity of a community. Alternatively, under a participation model of authenticity, students participate in the actual work of a professional community, 
engaging directly in the target community itself. Students adopt real roles in out of school communities and tasks are 'ecologically' authentic (Barab et al., 2000) to the degree to which learners engage in authentic practices of a community (Lave \& Wenger, 1991).

Reeves, Herrington and Oliver (2002) proposed ten characteristics of authentic activities for designers and teachers, based on an extensive literature review of the area. They then used this framework to discuss how online environments can facilitate authentic tasks. The authors contend that authentic tasks have real world relevance, are ill-defined, comprise complex sub-tasks to be investigated over a period of time, provide the opportunity to examine the task from different perspectives and are collaborative in nature. Furthermore, such tasks provide opportunities for learner reflections, are applied across different subject areas, are seamlessly integrated with assessment, involve the creation of valuable products and allow a diversity of solutions.

\section{DV tasks and authenticity}

Potter (2005) focused on ways that DV work can be used in an expressive and 'culturally authentic' mode. He found that very young children utilised the video medium to create a range of sophisticated and rich representations, and emphasised that children are operating in a medium which is familiar and culturally closer to their experiences of life outside the school than is usual with the school curriculum. Indeed, part of the motivational impact of DV projects seems to emanate from their capacity to engage students in real world problems (Jonassen, Peck \& Wilson, 1999) and relevant out of school interests, particularly their knowledge of TV and film (Parker, 2002). Another key factor is making sure that students' films reach a 'real' audience (Burn \& Reed, 1999; Coleman, Neuhauser \& Zwaag, 2004). Furthermore, Burden and Kuechel (2004) found that pupils respond better to digital assets produced by their peers and teachers (the language and appearance of some professional assets was a demotivating factor for some pupils.)

Shewbridge and Berge (2004) discussed the need for teachers to harness the natural interest that students show for these tasks, to create imaginative and authentic learning opportunities for students. These authors emphasised the increasing relevance of digital video production to education today and discussed benefits such as media literacy, active learning, experiential learning, play and motivation. There are many other papers in the literature describing authentic learning processes using student authored DV projects and associated learning benefits. For example, Levin (2003) described the authenticity of his high school history students' production of DV products telling the story of Holocaust 
survivors. A major goal of the project was to forge links with the community by meaningful engagement with the world outside the classroom.

In summary, there is a growing body of literature which is useful in developing understanding of the nature of authentic learning through use of student generated digital video. The study described in this paper set out to gain a deeper insight into this area and to expand on some issues regarding the authentic nature of DV tasks. We further explore the role of the audience and its relationship to authenticity, the authentic assessment of DV tasks, and other pedagogical practices that contribute to the authentic nature of DV tasks.

\section{The study}

In our study we sought to gain an understanding of the way that teachers and students interact and learn in classrooms in which practice using student generated digital video occurs. A qualitative research paradigm was used in this interpretive study (Erickson, 1986; Lincoln \& Guba, 1985) to examine the experiences occurring in five case study classrooms. The study explored four research questions concerning teachers' rationales, school context, learning outcomes and pedagogical approaches. (For papers discussing these questions and related findings, see Kearney and Schuck, 2005; Schuck and Kearney, 2006; Schuck and Kearney, 2005.) As well, we ensured that we remained open to questions and theories that might arise from the data in a grounded theory methodology (Strauss \& Corbin, 1998). Indeed, a strong theme to emerge in the study, and the subsequent focus of this paper, was the authentic nature of the DV tasks and related learning.

The research question that arose as these data were analysed and interpreted was:

What is the nature of authentic learning in this student generated digital video environment and how are its characteristics manifested? To gain an understanding of this question, we examined the nature of the observed tasks and the teaching approaches used in the various learning environments of each case in the study.

\section{Participants}

Five case schools were selected across K-12 (ages 5 to 17) so that there were both primary and secondary schools and a range of curriculum areas and pedagogical contexts for the use of the technology. The schools were located in two Australian states (New South Wales and Victoria) and comprised two state primary schools (District PS and Southern PS) and 
three secondary schools (Princes HS, Park HS and Pathways HS). One of the secondary schools was a state school and the other two were both Catholic system schools. The schools investigated were all well known as schools that were implementing innovative approaches using student generated digital video (see Schuck \& Kearney, 2004 for further details). Pseudonyms are used in this paper to protect individual teacher and school identities.

\section{Data collection and analysis}

Each school was visited by at least two members of the research team, which comprised the two authors and two research assistants. Data were collected in a number of ways. Initial open ended questionnaires were given to teachers and administrators to collect demographic information and views about administrative structures, and to probe rationales for use of student generated DV. Observation of lessons was conducted using a semi-structured observation schedule. Video of class activities was also taken (see Schuck \& Kearney, 2006a for discussion of emerging issues relating to our use of digital video as a methodological tool). Interviews were held with teachers, administrators and selected students in focus groups. Students were selected for these interviews by means of purposeful sampling (Bogdan \& Biklen 1998). Finally, artefacts made by the students were collected as well as school documentation about ICT management, rationale and use. The curriculum documents pertaining to the lessons were also examined.

The story of each case school was constructed and developed from the multiple sources of data on that case. After each field trip, researchers transcribed the data from notes, audio tapes, and video tapes. The research questions provided a framework for the case studies. After all case studies were completed, the final stage was to collaboratively consider the five cases in terms of the insights they provided regarding the four research questions, and look for common trends, discrete differences and influences that might have caused these differences. It was at this stage that the research question regarding authentic learning emerged.

\section{Sample DV tasks from study}

Over sixty different student generated digital video projects were part of the data in the study. Some samples discussed in this paper are introduced and summarised in Table 1 below.

A more comprehensive and specific discussion of the DV tasks encountered in the study can be found in Schuck and Kearney (2004). 
Table 1: Sample DV tasks from study

\begin{tabular}{|l|l|l|}
\hline Class / subject & \multicolumn{1}{|c|}{$\begin{array}{c}\text { Teacher / } \\
\text { school }\end{array}$} & \multicolumn{1}{|c|}{ Brief description } \\
\hline Yr 7 French & $\begin{array}{l}\text { Helga / } \\
\text { Pathways HS. }\end{array}$ & $\begin{array}{l}\text { Students making videos in French to send to their } \\
\text { sister school in France. }\end{array}$ \\
\hline $\begin{array}{l}\text { Yr 8 Science / } \\
\text { Maths }\end{array}$ & $\begin{array}{l}\text { Mal / Pathways } \\
\text { HS. }\end{array}$ & $\begin{array}{l}\text { Students were making animations of local } \\
\text { astronomy concepts such as eclipses and moon } \\
\text { phases. Maths students were filming objects } \\
\text { moving down a slope to inform a graphing } \\
\text { exercise }\end{array}$ \\
\hline Yr K & $\begin{array}{l}\text { Jayne / District } \\
\text { PS }\end{array}$ & $\begin{array}{l}\text { Children would film other students presenting } \\
\text { their daily news items. }\end{array}$ \\
\hline Yr 5/6 Group & $\begin{array}{l}\text { Nancy / } \\
\text { District PS }\end{array}$ & $\begin{array}{l}\text { 20 children formed a 'news team' to report on } \\
\text { school news and present a weekly web based } \\
\text { newsletter containing video based items. }\end{array}$ \\
\hline Yr. 3 & $\begin{array}{l}\text { Kate / Southern } \\
\text { PS. }\end{array}$ & $\begin{array}{l}\text { Children were studying human virtues by } \\
\text { making a video in which they portrayed a } \\
\text { particular 'virtue' and its benefits to others. }\end{array}$ \\
\hline Yr. 5/6 & $\begin{array}{l}\text { Michelle / } \\
\text { Southern PS. }\end{array}$ & $\begin{array}{l}\text { Children used video to develop metacognitive } \\
\text { skills. }\end{array}$ \\
\hline $\begin{array}{l}\text { Yr. 10 RE / } \\
\text { History }\end{array}$ & Ray / Park HS. & $\begin{array}{l}\text { RE students were producing a drama on Moses } \\
\text { and History students were doing a simulation of } \\
\text { a news item on the 1967 referendum. }\end{array}$ \\
\hline Yr. 11 IT & Ray / Park HS & Students were making advertisements. \\
\hline $\begin{array}{l}\text { Yr. 7 ESL/ Yr. } \\
\text { 10 English }\end{array}$ & $\begin{array}{l}\text { Carole / } \\
\text { Princes HS. }\end{array}$ & \begin{tabular}{l} 
Students were making 'infomercials'. \\
\hline
\end{tabular} \\
\hline
\end{tabular}

\section{The authentic nature of student generated digital video projects}

As indicated above, one main theme to emerge from the project's data from all five schools is the 'real world' nature of students' learning when they produce their own digital video products. This theme led to the posing of the question discussed previously: What is the nature of authentic learning in this student generated digital video environment and how are its characteristics manifested?

Numerous students and teachers perceived DV projects as very different in nature to other, more traditional class tasks, and indeed most students did not perceive these projects as 'school work' or 'study'. The following sections further probe the authentic nature of these projects with illustrative views of authentic learning and assessment that arose in these contexts. Data were ascertained from interviews and questionnaires, researcher observations and document analysis. 


\section{The nature of the observed tasks}

The following sections illustrate how the structure of the DV tasks encouraged authentic learning. The characteristics of authentic learning that were observed in these tasks arose from the open ended nature of the tasks, the way student autonomy and task ownership were encouraged in the tasks, the meaningful nature of the student roles in their groups, and the targeting of peers as the audience. Data illustrating these aspects of authentic learning are discussed below.

\section{Open ended tasks, student autonomy and task ownership}

The DV tasks we investigated were similar to real world tasks in that they were typically open ended and involved learner choice (Petraglia, 1998). Learners were given considerable control over their task development, and subsequently they displayed high levels of autonomy and ownership over their products (Chan, 2001).

Many students were given a broad directive and were required to choose the content of their film and, on a few occasions, the film genre and intended audience. They wrote their own scripts and storyboards and were creative with their filming. For example, the Year 10 students at Park CHS chose the medium in which to present their RE and History assignments and then had full responsibility for producing the material for the videos. This meant they chose how to present the material, they wrote the scripts, they researched the topic, and they came to their teacher when they needed to ask questions about the technology.

For example, the Year 10 History students at Park HS were studying the 1967 referendum on whether Aboriginals should be included in the census. They were asked to make presentations on this topic using the medium of their choice and one group chose to present their assignment in digital video format by making a DVD on the topic. They requested assistance from their IT teacher, Rory, and worked on the production both in and out of class time, often coming to Rory's computer lab during lunch. They scripted and acted, filmed, and edited in iMovie. They put in various effects to add to its professional appearance before copying it to a DVD to show their class. Their final production was a slick 10 minute DVD production involving the group's leader acting as the newsreader 'at the desk' of the Channel 7 news (set in 1967). During their news bulletin, they staged three interviews 'in the field' to probe pertinent issues surrounding the referendum, from different perspectives. Students acted as reporters and interviewees, integrating an impressive range of historical facts and appropriate humour (usually playing on the 1960s 'hippie' era) into their presentation. The influence of the real life news services was obvious in their production. 
A noteworthy aspect was the students' initiative in presenting their assignment in this way, and the motivation, enthusiasm and learning that was evident from doing this project. One of the students in the group explained later that the news format was a familiar one to most of their peers and they were very concerned about effectively communicating their idea to their peers.

It was really flexible and there were all the different techniques we could use, but in the end, we used it as a news report. This was a familiar form, because a lot of people watch the news every night, so this would make it more interesting for them as they would recognise that format.

Another student expressed similar ambitions: "We tried to do it [their DV task] in a way that would allow people [their peers] to understand, rather than just read a report. Just the way that we knew people our age would understand it. Also, to be funny."

The group knew the news format would be a familiar and comfortable one for their peers' viewing and this knowledge influenced their decision to go ahead with this film genre. Another student later explained how the 'neutral', unbiased nature of the news reporting genre allowed them to be impartial in their presentation of the topic.

We tried to give both points of view-it came from both ways. It [their production] had a point of view from the average person who did not really like it and there was [the other view] that this [Aborigines being included in the census] would be a break through and this would really happen.

Indeed, the news format provided the students with a powerful context to explore and present multiple perspectives on this issue. Their ownership of the task and the autonomy with which they acted was encouraged by the nature of the task and the technology. Similarly, Kate allowed her Year 3 students (Southern PS) to drive their DV activities. The children chose their groups and what virtue ('virtues' was the topic of their films) they would use in their project before working together on a detailed storyboard. These students also chose their audience and made suggestions for the final format of their film presentations. For example, one child suggested that they get the audience to give them notes on 'virtues' they had seen and another child suggested they develop cue cards to help with the talking.

Almost all teachers encouraged students to take a 'risk taking' approach to their movie making skill development, and encouraged them to learn from their mistakes. For example, Carole (Princes HS teacher) realised that several groups still needed to work on their storyboards but she allowed them to begin filming and make their own mistakes to realize that they needed more in their storyboard. Students looked at their footage in small groups and the teacher circulated and assisted. They learned from their 
filming mistakes and re-filmed if necessary. Similarly, the six year old students from Jayne's K class (District PS) were given considerable autonomy in their daily filming of the class news. After brief initial instruction, she assumed students knew how to use the camera and that they would ask questions if they needed help. Jayne said she thinks of her students as "directors" and in this way, she let students "realise themselves that smoother filming is better". Students had recently started to notice aspects relating to sound recording and use of the camera's microphone.

Congruent with the high levels of student autonomy were high levels of task ownership. This ownership was evident in the pride they showed when discussing their artefacts with us. For example, when students displayed their work in Mal's Year 8 Science lesson (Pathways HS), they would point at the video presentation, sit up straight in their seats and look proud (but faintly embarrassed), when their video was shown. Teachers also commented on the ownership aspect of student generated digital video. For example, Colin (Year 4 teacher at Southern PS) thought the group ownership aspect was a powerful factor in his rationale for using DV projects: "This is a team thing and they get ownership by seeing it on the screen and they can put it on their CD and take it home to show their parents."

\section{Meaningful student roles and interaction}

The complex nature and large scope of the DV projects in the study dictated a group learning structure and students subsequently adopted meaningful roles and interacted in ways that imitated real world tasks. The process of filming peers acting was particularly meaningful for students.

Generally, there were two ways that students divided tasks within their groups: an 'expert system' and a 'role rotation system'. In some cases, students chose the area to which they wished to contribute, for example, script writing, acting or directing the video. For example, the Year 3 class at Southern PS used an 'expert system'. The teachers felt it was vital that students should be empowered to become leaders in the classroom and in the school. Consequently, as students became experts in the various applications and equipment they became a resource for others. The idea was to 'ask three other people before asking the teacher' and the children were supplied with a 'yellow pages' of experts. In other cases, they rotated the roles. For example, in the example discussed above of the Year 10 History projects at Park HS, students all had a turn at doing the different tasks. In some cases, students indicated that they did not like filming or editing, while others indicated that they did not want to 'act' in the video. Workable group arrangements seemed to develop through the students' negotiations with each other and authentic teamwork skills were a valued outcome from these projects. Conflicts appeared to be readily resolved, and 
in many cases, the friendship groups that formed worked extremely well together, as members shared their goals and often worked out of school time to complete their tasks.

Students also were acutely aware of filming their peers. The researchers observed many filming episodes across the five case studies covering footage of both people and inanimate objects, but students showed particular enthusiasm when filming their peers. They especially enjoyed acting in their own dramas and all students delighted in being characters in their own movie. For example, in their focus group interview, some Year 7 French students (Pathways HS) stated unanimously that their favourite DV production task at school was filming friends acting. Their teacher agreed with this perception and she had noticed many times that her students love to see themselves and their friends on the screen and this contributed to the authentic nature of the tasks.

A project that illustrated the meaningful team roles that developed was the Year 5/6 news group that existed at District PS. This project involved approximately twenty senior primary students (all volunteers) who formed an editorial news team to prepare and publish weekly items for the school community on the school's intranet based newsletter. Video clips were used to capture a variety of events or episodes, including interviews and general commentary. The students used iMovie to edit their videos, including commentary and text additions. They received stimulus ideas from programs they had seen on TV such as the news, movies and more specific aspects such as special effects and digital animation.

The level of teamwork was high, there were clear roles and the students were generally independent in these roles. They met regularly to discuss possible items and write about current events in the school. The students were responsible for both content and technical issues and did their own filming, editing and production. The children had a variety of roles, including technical officer, interviewers, writers and sports reporters. The team worked well together and supported each other to achieve the best possible outcomes. Indeed, Nancy had recently noticed an improvement in the way her students worked together on their shared projects such as in the way they managed roles and responsibilities, their discussion of what they were doing, and general negotiating skills. She had often observed students sharing and cooperating and encouraging each other and arguments or tensions between students had become rare.

It was an excellent simulation of a real world (news) production team that potentially involved the whole school community (anyone in the school was able to submit an item to the team for consideration). The main audience was the school community, especially other children in the 
school. The students received guiding support from the teacher or librarian and indeed, Nancy perceived her main teaching role as a 'sounding board' for students.

Targeting peers as a relevant audience

Projects in the study were aimed at a range of target audiences from teachers and parents to community members outside the school. However, many students commented that having their peers as the main target audience provided them with an extra incentive to make a worthwhile film as well as providing an opportunity to use appropriate language and humour. For example, a Yr 7 French student from Pathways HS believed that knowing her peers were going to look at her production motivated her to understand the (French language) content of her project: "It helps you to learn because if it goes up on the TV then the people [peers] really have to read it to understand what you're saying." Indeed, the tasks acted as a catalyst for students to project their personalities to their peers in an authentic way. For example, another Yr 7 French student from Helga's class (Pathways HS) made the following perceptive comments: "The pictures represent you... yes, they show your own personality." In this way, students' awareness of their peers as the target audience was an incentive for them to understand the curriculum material and related concepts and to carefully select and use appropriate language in their films.

In many projects, students used their videos as a vehicle to present a story to their class friends. Many students said they appreciated this opportunity to make a video based class presentation as an alternative to a 'live' presentation. They believed that the video alternative reduced the anxiety of a live class presentation in front of their peers and improved their performance. For example, Ashleigh (Yr. 8 student from Pathways HS) mentioned in a student focus group:

Presenters do not need to get nervous as initially, the presentation is just in front of their friends for the camera. People are a lot better at doing them [a film], as they are in front of the camera and not in front of the whole class.

Everything can be prepared beforehand and the product displayed for the class. They then do not have people laugh at them.

Students appreciated the extra time they had to edit and refine their video presentations. This enhanced their confidence and communication skills.

\section{Teaching approaches}

The teaching approaches that were used reflected teachers' rationales for using digital video and generally highlighted their desire to offer students authentic learning opportunities. We indicate below some of the approaches used and the way they illustrated authentic learning. 
Use of a contemporary communication mode and targeting new literacy skills

Many teachers mentioned that part of their rationale for using DV in their teaching was its contemporary relevance to young people and its potential use as a fresh communication medium. Many students were very familiar with the video medium from their media rich, (often out of school) 'digital culture' and hence they were communicating in a 'culturally authentic' mode (Potter, 2005). A number of the teachers expressed a desire to explore new, interesting ways of teaching using contemporary tools they knew would appeal to students. For example, Bruce (ICT coordinator at Pathways HS) also stressed that one reason he liked to use DV in his teaching was because it allows students to communicate a message in a unique and fresh way. Similarly, Helga (French teacher) said her Year 7 students were bored with tapes and textbooks and she initially got interested in DV because of her perceived need to make her lessons more interesting and allow students to use a new medium to communicate and develop their language skills. Nancy also commented on the contemporary nature of DV tasks:

Digital Media is 'the real stuff'! Kids can make use of software and tools to
create things that are of a professional standard. It starts with things they've
seen within the world or within the media that they're wanting to model or
they're wanting to put their ideas and experiences into that style of a
presentation... Digital video is a new way of talking about ideas, setting
scenes, influencing people, emotional... pulling music into it etc. It can
contain big ideas for kids to work with. (Interview with Nancy, Teacher,
Districts PS)

She also mentioned that students' video based products were very much 'in tune' with the real world and as such, a final product could be utilised in relevant ways. For example, her students were creating video based news reports to be included in a weekly online school newsletter (discussed in previous section).

Students perceived the development of their movie making skills as a highly relevant part of their learning in their projects. When asked in their interviews about their learning, students often emphasised their movie making skill development. For example, the Yr 7 IT students (Princes HS) liked learning about technology, learning for the future, interacting with friends and learning to direct. They realised that they could practise these skills and might be an actor or director one day. One student recognised the usefulness of his new movie making skills to his future: "It [DV] will help you in later life. For example, as an electrician or photographer." Indeed, the two Year 7 teachers at Princes HS emphasised students' movie making skill development as highly relevant to their potential work related activities on leaving school. 
Many teachers thought that a major reason for using DV tasks in their classrooms was the potential development of students' ability to make sense of the video medium and to critically analyse film genres from the world around them. For example, Michelle (Year 5/6 teacher at Southern PS) had identified links between English syllabus outcomes and media literacy outcomes, and married these learning outcomes as an integral part of her English program. She worked heavily on immersing her students in 'what is great video'. Similarly, at Park HS, there was a big focus on developing students' media literacy through the use of DV projects as a mandatory part of the English Syllabus. For example, students looked at different camera shots and how they help 'tell different stories'. In his interview, Ray (Park HS teacher) mentioned an increased student awareness of the advertising genre as a pleasing literacy outcome for his Year 11 IT students. He believed that his students' productions of advertisements helped them to understand how advertisements convey messages. Indeed, Jayne (teacher at District PS) thought the use of student generated digital video in her $\mathrm{K}$ class had helped her children to develop a focus, and become more analytical of films and advertisements.

Authentic assessment practices

Self and peer assessment practices were a strong part of the assessment of DV tasks in the study and in some case schools, these procedures were integrated with e-portfolio assessment. Teacher observation and frequent feedback throughout the production process also formed a key part of teacher assessment practices. These practices were supported by literature suggesting that non-authentic assessment (as measured by grades and tests etc) can undermine task authenticity (eg. Barab et al, 2000).

Some teachers encouraged students to create video clips as a vehicle for self assessment of their learning. For example, Michelle's Year 5/6 students (Southern PS) would periodically film themselves, effectively creating 'chapters' in the 'story' of their learning. She wanted her children to be reflective in their learning and she believed that inclusion of these 'reflective clips' made for a more meaningful e-portfolio. (Indeed, some students from this class cleverly made their reflections using a music video genre.) Another teacher, Kate, used her students' more informal self assessments as a barometer for evaluating the students' work. She believed that her children were very critical of themselves and could easily self assess whether they were happy with their work and felt their message had been delivered effectively.

Carole's students made similar reflective clips in her Year 10 English class at Princes HS. Her students reflected on what and how they were learning, what they had done well, what their weaknesses were, how the teacher could support them better and what they needed to do to improve. 
According to Carole, their self assessments were revelatory. She found that their evaluations often revealed achievement of learning outcomes that otherwise may not have been obvious to her, for example some students reflected on quite sophisticated movie making and media literacy skills.

Group members were frequently observed giving each other formative peer feedback during the process of making their films. Colin (teacher at Southern PS) reported on this aspect of his Year 4 children's projects in his post-lesson interview: "They showed their work to others. That was the main thing that stood out!" This peer feedback process contributed to a heightened sense of awareness of their film's attributes and flaws. Indeed, a key aspect of authentic learning here was the way that students gained feedback on their work. Often the students' best and most immediate 'feedback' on their work was their viewing (either via the small camera screen or later, on the computer) of their own films. This feedback on their work is very different (and often supplementary) to other methods of deferring to a supervising teacher or other "expert". Students see their work from different perspectives as they listen to the comments and experiences of others in their group (Shewbridge \& Berge, 2004).

Teachers often relied on their own observations for informal assessment of many learning outcomes, including development of movie making skills, language and teamwork skills, conceptual understanding and affective outcomes. The emphasis here was on both the process and the final product. For example, Colin placed emphasis on observing students' conversations and their general use of relevant language in assessing their conceptual development. He also observed and gauged their learning in the pieces of writing they did after their projects. Likewise, Kate commented on the language used by her Year 3 students at Southern PS during and after their projects and observed behaviour changes in students. For example, she observed increased student understanding of their 'virtues' topic by listening to the children's conversations: "You can see if children have 'taken on board' the content of the virtues by their language in what they say."

An example of authentic assessment in the Year 7 ESL class at Princes HS illustrates the variety of ways in which authentic assessment can be implemented. A major outcome of Carole's (Princes High) lesson with her Year 7 ESL students was to practise oral and written English. The way these students engaged in the various aspects of the lesson was quite impressive. The technology afforded the students the chance to practise their oral English through interacting with peers and adopting roles that required their understanding of language that differed from their own everyday speech. The story boarding also mandated their recording of written descriptions, again affording English practice. 
Student learning was assessed in numerous ways. Carole evaluated both the quality of students' final products and made formative assessments of students' learning by reading their learning logs and making informal observations. She valued the final products in terms of the overall quality of their final production, as well as smaller components such as the use of music, framing of shots, use of special effects, and how effectively it communicated the intended message. She also placed an equally strong emphasis on the process of the creation of the DV by assessing students' storyboards and observing their activities in the classroom. She made informal observations of student behaviour and listened to students' conversations. She focused here on aspects such as how well groups were working together, reflecting and fixing mistakes. Finally, her students made peer and self assessments of their work in their learning logs.

\section{Summary}

The DV tasks in this study allowed students to communicate through a contemporary medium in fresh ways, and helped them develop new literacy skills that were perceived as being relevant to their future careers (Yildiz, 2003). Peers provided a relevant and motivating audience and students particularly enjoyed filming their peers. They also enjoyed real life film production roles and developed teamwork skills that will be useful in later life. Tasks were open ended, demanded a high level of student initiative and resulted in useful products to share with peers. The authentic nature of DV tasks was enhanced by practices such as self and peer assessment and informal teacher observations.

\section{Discussion}

Authentic learning in the context of DV projects comprised learning in ways that fitted with real world contexts, where the learning was motivated and developed by the context. Skills and concepts for 'effective living' in contemporary society were developed, although most tasks lacked links to out of school professional communities. Students enjoyed this unique opportunity to 'find a voice' through their DV tasks, in an attempt to communicate in a contemporary way with a wide peer audience. Indeed, students showed an acute awareness of their peers as both the subjects of their filming and the target audience for their projects and this awareness was a pivotal factor in their notions of authenticity.

\section{Effects of peer audience}

Numerous researchers have noted that the creation of DV or other multimedia 'products' was made more authentic by increasing the extent to which the products were shared with real audiences (Burn \& Reed, 1999; 
Coleman et al., 2004; CTGV, 1990). We have attempted to further explore the links between audience and authenticity in the context of DV tasks. In many cases in this study, students were acutely aware of their peers as an authentic audience for their films. Their knowledge of audience was central in students' choice of themes, language, props and ways of presenting information in their videos, and also motivated students to present high quality work. This relationship between 'author and audience' was a key influence on students' development of motivation, critical analysis skills and conceptual learning outcomes and seemed to enhance the 'use value' (Barab et al., 2000) of these tasks for students.

Student awareness of their peers as the main target audience was noted as a significant factor in students' development of motivation. We observed that DV work initially provided extrinsic motivation for many students, especially 'reluctant learners'. For example, the novelty of using contemporary equipment and the perception of DV work as 'fun' contributed to initial task engagement. However, inherent in many DV projects we observed were classic elements of 'situated motivation' (Paris \& Turner, 1994) such as challenge, choice, control and collaboration. Although students did not perceive their DV projects as 'work', they did report a sense of challenge at various stages of their projects and many students reported a sense of satisfaction and pride when their video was completed. High levels of choice and various dimensions of control, such as students being able to choose roles, pace themselves and get prompt feedback, were also a feature of many DV tasks, as discussed in previous sections. There were ample opportunities to interact with peers in meaningful ways (such as filming each other acting) and these aspects had a positive influence on the perceptions of task ownership. However, a key dynamic underlying all of these aspects was the opportunity for students to project their personalities to their peers through a contemporary medium. Consequently, many learners became more interested in the actual content and topics being studied as the projects progressed. For example, we observed some abstract and probably unappealing DV task topics but by the end of these lessons, we observed a significant degree of genuine student interest in these topics.

Primed by the anticipation of their peers as the intended audience, students also developed the ability to critique aspects of their own films and also investigate ways of making the content of their films accessible. They found it important to use genres that their peers would understand and enjoy. This often involved developing a deeper understanding of the underlying concepts so that they would be able to present these ideas in different ways. In this way, students' awareness of their peers as the target audience was an incentive for them to understand the curriculum material and related concepts and language in their film. 


\section{Improving authenticity in DV tasks}

The tasks in the study shared many of the characteristics of authenticity as discussed by Reeves et al. (2002). The tasks provided students with contemporary ways of communicating, culminating in a product that could be shared and discussed with a real audience. Real world contexts, such as the news or advertising genres, provided students with an avenue to explore issues from multiple perspectives. Tasks were open ended, involved high levels of choice and encouraged student initiative. Authentic assessment practices were often seamlessly integrated into DV tasks, and small group practices provided students with relevant roles and meaningful, collaborative interactions.

One aspect that warrants more attention is creating opportunities for students engaged in DV tasks to reflect on their learning. Reeves at el. (2002) advocate that well-designed authentic activities should give learners opportunities to "reflect on their learning both individually and socially" (p. 564). Although there were exemplary cases of this occurring, there were numerous cases in the study where final class presentations became more of a 'show and tell' and lacked insightful discussion of underlying themes and concepts. Indeed, evidence of ongoing reflections via some type of learning journal was minimal. Time constraints were a factor here teachers allowed students large amounts of time to complete their projects, leaving minimal time for either journal writing or class dialogue centred on students' culminating class presentations. Further research is needed into how new technologies such as digital video annotation tools, (text and video) web logs, and e-portfolio software can support student reflection during the DV production process, and how these contemporary reflection tools might add to learner perceptions of authenticity.

Another interesting aspect that warrants further research is the effect of a wider peer audience that reaches beyond the boundaries of the school. There were only a few cases where students were targeting peers outside their school. For example, the Year 7 French students (Pathways HS) were exchanging videos with a sister school in France. Indeed, the year 5/6 children (District PS) were keen to expand their work and link up with other schools around the world to share surveys, videos and make comparisons. To what extent does a wider peer audience affect the learner perceived authenticity of DV tasks? Indeed, in what ways can peers from other learning communities collaborate on jointly owned DV tasks and how does this affect their perception of task relevance?

Although there was a high degree of authenticity at the task and process levels, 'ecological authenticity' (Barab et al., 2000) was seldom a feature of the DV tasks in this study. The time and physical constraints of the school 
system again made it difficult for many teachers to immerse their students into authentic communities of practice that 'apprentice the learner' into real world environments (such as professional film making, linguistic, scientific or industrial practices.) However, we did see some attempts to at least make links with other professional communities. For example, a teacher at Southern PS invited an expert geologist to come to their school and engage in a science discussion initiated by the students' films. As online technologies create more opportunities for such collaborations with out of school, expert communities (Shewbridge \& Berge, 2004) and indeed, other school communities, further research is needed into how these interactions might affect students' views of authenticity. Indeed, investigating these kinds of questions will help meet increasing challenges to 'bridge the gap' between learning environments and ever evolving 'real life' communities of practice (Stein, Isaacs \& Andrews, 2004).

\section{Conclusion}

As contemporary media permeate education, an understanding of associated skills, tools and processes is needed to engage students in authentic learning processes. The cases we have discussed here, together with the beliefs and perceptions of both students and teachers, clearly indicate that student generated digital video projects can be used to develop authentic learning. In contrast to more traditional tasks where materials and processes are imposed on students by teachers, DV projects were typically student driven and required a high degree of student initiative. Students collaboratively designed their own projects, produced them and evaluated them. Many were motivated by these processes, particularly if their peers were the target audience. Students enjoyed the unique opportunity to 'find a voice' through their DV tasks, in an attempt to communicate with their peer audience. Indeed, they were aware that other groups would be viewing their final product and providing their own peer feedback, and this awareness acted as a catalyst for the critical analyses of their own films. DV projects were seen as contemporary and relevant learning tasks.

\section{References}

Barab, S.A., Squire, K.D. \& Dueber, W. (2000). A co-evolutionary model for supporting the emergence of authenticity. Educational Technology Research $\mathcal{E}$ Development, 48(2), 37-62.

Bogdan, R. \& Biklen, S. (1998). Qualitative research for education. An introduction to theory and methods. Boston: Allyn and Bacon.

Brown, J. S., Collins, A. \& Duguid, P. (1989). Situated cognition and the culture of learning. Educational Researcher, 18(1), 32-42. 
Burden, K. \& Kuechel, T. (2004). Evaluation report of the Teaching and Learning with Digital Video Assets Pilot 2003-2004. UK: BECTA. [verified 9 May 2006] http://www.becta.org.uk/page_documents/research/evaluation_dv_assets03.pdf

Burn, A. \& Reed, K. (1999). Digi-teens: Media literacies and digital technologies in the secondary classroom. English in Education, 33, 5-20.

Chan, V. (2001). Learning autonomously: The learners' perspectives. Journal of Further and Higher Education, 25(3), 285-300.

Coleman, B., Neuhauser, J. \& Zwaag, C. (2004). 'Play it again, Zack!' Video classrooms: proven practice and projects. In Proceedings of World Conference on Educational Multimedia, Hypermedia and Telecommunications 2004 (pp. 4723-4728). Norfolk, VA: AACE.

CTGV (Cognition and Technology Group at Vanderbilt) (1990). Technology and the design of generative learning environments. Educational Technology, 31(5), 34-40.

Erickson, F. (1986). Qualitative methods in research on teaching. In M. Wittrock (Ed), Handbook of research on teaching, (3rd ed. pp. 119-161). New York: Macmillan.

Jonassen, D., Peck, K. \& Wilson, B. (1999). Learning with technology. A constructivist perspective. New Jersey: Prentice Hall.

Kearney, M. \& Schuck, S. (2005). Students in the Director's Seat: Teaching and learning with student-generated video. In P. Kommers \& G. Richards (Eds), Proceedings of Ed-Media 2005 World Conference on Educational Multimedia, Hypermedia and Telecommunications pp. 2864 -2871. [verified 11 May 2006] http://www.ed-dev.uts.edu.au/teachered/research/dvproject/pdfs/edmedia05.pdf

Lave, J. \& Wenger, E. (1991). Situated learning: Legitimate peripheral participation. New York: Cambridge University Press.

Levin, H. (2003). Making history come alive: Students interview Holocaust survivors on camera and publish their stories on the web. Learning and Leading with Technology, 31(3), 22-27. [verified 11 May 2006]

http:/ / www.howardlevin.com/download/iste-11-03.pdf

Lincoln, Y. \& Guba, E. (1985). Naturalistic inquiry. Newbury Park: Sage Publications.

Paris, S.G. \& Turner, J.C. (1994). Situated motivation. In P.R. Pintrich, D.R. Brown \& C.E. Weinstein (Eds), Student motivation: Cognition and learning (pp.213-237). Mahwah, NJ: Erlbaum.

Parker, D. (2002). Show us a story: An overview of recent research and resource development work at the British Film Institute. English in Education, 36(1), 38-44.

Petraglia, J. (1998). The real world on a short leash: The (mis)application of constructivism to the design of educational technology. Educational Technology Research \& Development, 46(3), 53-65.

Potter, J. (2005). 'This brings back a lot of memories': A case study in the analysis of digital video production by young learners. Education, Communication $\mathcal{E}$ Information, 5(1), 5-23. 
Radinsky, J., Bouillion, L., Hanson, K., Gomez, L., Vermeer, D. \& Fishman, B. (1998). A framework for authenticity: Mutual benefits partnerships. Paper presented at the annual meeting of the American Educational Research Association, San Diego, CA.

Radinsky, J., Bouillion, L., Lento, E. \& Gomez, L. (2001). Mutual benefit partnership: A curricular design for authenticity. Journal of Curriculum Studies, 33(4), 405-430.

Reeves, T., Herrington, J. \& Oliver, R. (2002). Authentic activities and online learning. In A. Goody, J. Herrington \& M. Northcote (Eds), Quality Conversations: Research and Development in Higher Education, Vol 25, 562-567. Jamison, ACT: HERDSA.

http://www.ecu.edu.au/conferences/herdsa/main/papers/ref/pdf/Reeves.pdf

Schuck, S. \& Kearney, M. (2006, in press). Capturing learning through studentgenerated digital video. Australian Educational Computing, 21(1).

Schuck, S. \& Kearney, M. (2006a, in press). Using digital video as a research tool: Ethical issues for researchers. Journal of Educational Multimedia and Hypermedia, 15(4).

Schuck, S. \& Kearney, M. (2005). Teachers as producers, students as directors: Why teachers use student-generated digital video in their classes. In Proceedings of the Apple University Consortium Conference 2005 (Hobart, Sept), 11.1-11.13. Sydney: Apple Australia. [verified 10 May 2006] http://www.eddev.uts.edu.au/teachered/research/dvproject/pdfs/auc05.pdf

Schuck, S. \& Kearney, M. (2004). Students in the Director's Seat: Teaching and Learning with Student-generated Video. A Research Report. Sydney: UTS. [verified 10 May 2006] http://www.ed-dev.uts.edu.au/teachered/research/dvproject/home.html

Shewbridge, W. \& Berge, Z. (2004). The role of theory and technology in learning video production: The challenge of change. International Journal on E-Learning, $3(1), 32-39$.

Stein, S., Isaacs, G. \& Andrews, T. (2004). Incorporating authentic learning experiences within a university course. Studies in Higher Education, 29(2), 239258.

Strauss, A. \& Corbin, J. (1998). Basics of qualitative research: Techniques and procedures for developing grounded theory. Thousand Oaks, CA: Sage Publications.

Yildiz, M. N. (2003). Teaching media literacy through video production. Proceedings of World Conference on Educational Multimedia, Hypermedia $\mathcal{E}$ Telecommunications 2003 (pp. 1648-1651). Norfolk, VA: AACE.

Dr Matthew Kearney and Associate Professor Sandy Schuck

Faculty of Education, Kuring-gai Campus

University of Technology, Sydney

PO Box 222 Lindfield NSW 2070, Australia

Email: matthew.kearney@uts.edu.au, sandy.schuck@uts.edu.au

Web: http:/ / www.education.uts.edu.au/ 